\title{
Ranging behavior of female and male Shiny Cowbirds and Screaming Cowbirds while searching for host nests
}

\author{
Romina C. Scardamaglia* and Juan C. Reboreda
}

Departamento de Ecología, Genética y Evolución, and IEGEBA-CONICET, Facultad de Ciencias Exactas y Naturales, Universidad de Buenos Aires, Buenos Aires, Argentina

* Corresponding author: rscardamaglia@ege.fcen.uba.ar

Submitted March 8, 2014; Accepted May 24, 2014; Published August 13, 2014

\begin{abstract}
Brood-parasitic cowbirds are hypothesized to search for and locate host nests within a relatively constant area, as this is presumed to facilitate the monitoring of nests over time and the synchronization of parasitism with host laying. We tested this hypothesis in Shiny Cowbirds (Molothrus bonariensis) and Screaming Cowbirds (M. rufoaxillaris), two cowbird species that differ in host specificity and, apparently, in social mating system, by radio-tracking females and males for 3-6 consecutive days and determining individual daily morning ranges and cumulative morning ranges. In Shiny Cowbirds, the mean size of morning daily ranges and cumulative morning ranges was larger for males than for females, but we did not find a difference between the sexes in range size for Screaming Cowbirds. In both species, there was extensive overlap in the morning ranges of individual females between consecutive days, and the addition of new area to their ranges decreased over time. For both Shiny and Screaming cowbirds, morning ranges of conspecific females radio-tracked the same day overlapped, indicating lack of territoriality. Male and female Screaming Cowbirds that were trapped together were also spatially associated during radio-tracking, indicating social monogamy. Most radio-tracked Shiny and Screaming cowbirds used mainly one roost, relatively close to their morning ranges, which was maintained throughout the breeding season. Our results show that Shiny and Screaming cowbird females use relatively constant areas for nest searching and that Screaming Cowbirds are socially monogamous.
\end{abstract}

Keywords: brood parasitism, radio telemetry, nest searching, social monogamy, Molothrus bonariensis, Molothrus rufoaxillaris

\section{Áreas de acción de hembras y machos de Molothrus bonariensis y M. rufoaxillaris durante la búsqueda de nidos de hospedadores}

\section{RESUMEN}

Pusimos a prueba la hipótesis que los tordos parásitos de cría buscan y localizan nidos de hospedadores dentro de un área relativamente constante, ya que esto facilitaría el monitoreo de nidos a través del tiempo y la sincronización del parasitismo con la puesta del hospedador. Testeamos esta hipótesis en Molothrus bonariensis y M. rufoaxillaris, dos especies que difieren en su especificidad de uso de hospedadores $y$, aparentemente, en su sistema de apareamiento social, mediante radio telemetría de hembras y machos durante 3-6 días consecutivos, determinando las áreas de acción diarias y las áreas de acción acumuladas. En M. bonariensis, el tamaño medio de las áreas de acción diarias y de las áreas de acción acumuladas fue mayor para los machos que para las hembras, pero no encontramos diferencias entre sexos en $M$. rufoaxillaris. En ambas especies, hubo un extenso solapamiento de las áreas de acción de cada hembra en días consecutivos y la incorporación de área nueva disminuyó a través del tiempo. Tanto para M. bonariensis como para M. rufoaxillaris, las áreas de acción de hembras conespecíficas monitoreadas en un mismo día se solaparon, indicando ausencia de territorialidad. Los machos y hembras de $M$. rufoaxillaris que fueron capturados juntos se mantuvieron asociados espacialmente durante el monitoreo, indicando monogamia social. La mayoría de los individuos de $M$. bonariensis y $M$. rufoaxillaris monitoreados usaron principalmente un dormidero relativamente cercano a sus áreas de acción, el cual fue mantenido durante la temporada reproductiva. Nuestros resultados muestran que las hembras de $M$. bonariensis y $M$. rufoaxillaris usan áreas relativamente constantes para buscar nidos y que existe monogamia social en $M$. rufoaxillaris.

Palabras clave: parasitismo de cría, radiotelemetría, búsqueda de nidos, monogamia social, Molothrus bonariensis, Molothrus rufoaxillaris 


\section{INTRODUCTION}

Obligate avian brood parasites, such as cuckoos and cowbirds, lay their eggs in the nests of other species (the hosts) who thereafter provide all necessary parental care on the parasite's behalf (Rothstein and Robinson 1998, Spottiswoode et al. 2012). This reproductive strategy requires parasites to develop special abilities, such as being able to select an appropriate host species (Teuschl et al. 1998, Payne et al. 2000, Langmore and Kilner 2007), search for and locate nests that are suitable for parasitism (Wiley 1988, Honza et al. 2002, Fiorini and Reboreda 2006, Soler and Pérez-Contreras 2012), and return to suitable nests to lay eggs within the appropriate time frame (Moskát et al. 2006, Fiorini et al. 2009). As an example, cowbird parasitism occurs just before sunrise (Scott 1991, Peer and Sealy 1999, Gloag et al. 2013), and during the rest of the day females search for host nests that they may parasitize on subsequent days (Norman and Robertson 1975, Wiley 1988, Gloag et al. 2013). Cowbirds locate nests mainly by cryptically watching the activities of hosts in likely habitats (Norman and Robertson 1975, Wiley 1988, Kattan 1997), but they also locate nests by systematic searching (Fiorini and Reboreda 2006). Thus, typical behavior of cowbird females during the breeding season consists of searching for potential hosts' nests, to which they return for laying when their own condition (egg availability) and the state of the host's nest (host laying) coincide. Also, females should avoid laying in nests in which they have already laid eggs to avoid competition between their own offspring (Hahn et al. 1999, Trine 2000, Hoover 2003, McLaren et al. 2003, Goguen et al. 2011). Accordingly, a recent study has indicated that Shiny Cowbird (Molothrus bonariensis) females do not return to lay a second egg in a nest that they have already parasitized (Gloag et al. 2014), and several studies of Brown-headed Cowbirds have found a similar lack of repeat parasitism (Alderson et al. 1999, McLaren et al. 2003, Ellison et al. 2006; but see Rivers et al. 2012).

Cowbird parasitic behavior makes special demands on information processing, because at the time that a parasitic female is ready to lay an egg, she may face choices among several host nests within her home range. Since nests can only be parasitized successfully during the host's laying period, each nest is available only for a brief period, and once parasitized it should be erased from the set of putative available nests (Clayton et al. 1997, Gloag et al. 2014). This increased demand for remembering the location and status of host nests is associated with a relative enlargement of the hippocampus (Sherry et al. 1993, Reboreda et al. 1996), a brain region in vertebrates that is involved with processing spatial information (O'Keefe and Nadel 1978). This enlargement is present in the sex that searches for host nests: females in Shiny and
Brown-headed cowbirds ( $M$. ater), and females and males in Screaming Cowbirds (M. rufoaxillaris; Sherry et al. 1993, Reboreda et al. 1996). Females of the Brown-headed Cowbird performed significantly better than males in a foraging task that evaluated spatial memory (Guigueno et al. 2014), further supporting the hypothesis that spatial cognition is adaptively specialized in brood-parasitic cowbirds. Also, relative hippocampus volume is larger during the breeding season than during the nonbreeding season, and the sexual dimorphism present in Shiny Cowbirds in summer is not found in winter, indicating neuroanatomical plasticity associated with seasonal changes in spatial memory demands (Clayton et al. 1997).

Although there is general interest in understanding the use of space by cowbirds at the time that they search for host nests, most studies of their daily movements during the breeding season have focused on habitat use or the association between females and males, and all studies have been conducted on the Brown-headed Cowbird (i.e. Dufty 1982, Rothstein et al. 1984, Teather and Robertson 1985, Thompson 1994, Gates and Evans 1998, Hahn et al. 1999). These studies have shown that females spend the morning in host-rich breeding areas and commute to feeding areas for the rest of the day (Rothstein et al. 1984, Thompson 1994, Gates and Evans 1998). With regard to the association between females and males, some authors observed that the sexes engaged in extended associations through the breeding season (Dufty 1982, Teather and Robertson 1986), while others observed that there were no prolonged pair bonds (Rothstein et al. 1984) or that females were generally alone in the morning (Gates and Evans 1998). Except for the work of Hahn et al. (1999), none of these studies analyzed whether females used characteristic individual home ranges throughout the breeding season.

In this study, we analyzed individual morning ranges of Shiny and Screaming cowbirds during the breeding season. Our study differs from previous ones in that we determined individual daily morning ranges during several consecutive days and used these data to assess whether females and males had characteristic individual ranges when they searched for host nests. Shiny Cowbirds are extreme generalist brood parasites and their eggs have been found in the nests of more than 260 species, of which $\sim 100$ have been confirmed to successfully rear cowbird young (Lowther 2013). During the breeding season Shiny Cowbirds parasitize host nests before sunrise and spend the rest of the day foraging and visiting potential host nests (Gloag et al. 2013). Screaming Cowbirds are one of the most specialized brood parasites as they use almost exclusively one host, the Bay-winged Cowbird (Agelaioides badius; Fraga 1998, De Mársico et al. 2010). Both of these cowbird species roost communally in large numbers, either in single- or mixed-species groups (Fraga 1986, Cruz et al. 
1990, Feare and Zaccagnini 1993). Female Shiny Cowbirds search for host nests without the assistance of males (Wiley 1988, Kattan 1997, Gloag et al. 2013), while Screaming Cowbirds are usually seen in pairs, even during the nonbreeding season (Fraga 1986, Mason 1987, De Mársico and Reboreda 2008). This association has led some authors to suggest that Screaming Cowbirds are socially monogamous and that males and females search for host nests together (Friedmann 1929, Mason 1987).

Our general hypothesis was that cowbirds would search for and locate host nests within a relatively constant area, which would allow them to track nests through time and therefore synchronize parasitism with host laying. Accordingly, we expected that morning ranges of individual females would overlap in consecutive days. Because female Shiny Cowbirds search for host nests without the assistance of males, while Screaming Cowbirds are assumed to search for host nests in pairs, we expected that morning ranges would differ between the sexes in Shiny Cowbirds but not in Screaming Cowbirds. In addition, if male and female Screaming Cowbirds are socially monogamous, pairs caught together should remain spatially associated throughout time.

\section{METHODS}

\section{Study Site}

We conducted our study within $\sim 1500$ ha at the private reserve "El Destino" ( $\left.35^{\circ} 08^{\prime} \mathrm{S}, 57^{\circ} 23^{\prime} \mathrm{W}\right)$ near the town of Magdalena, Buenos Aires province, Argentina, during the breeding seasons (October-February) of 2010-2011 and 2011-2012. The study site is almost flat marshy grassland with interspersed woodland patches dominated by Celtis ehrenbergiana and Scutia buxifolia. Shiny Cowbirds and Screaming Cowbirds are year-round residents in this area. The main hosts of Shiny Cowbirds are Chalk-browed Mockingbirds (Mimus saturninus; frequency of parasitism 89\%; Gloag et al. 2012) and House Wrens (Troglodytes aedon; frequency of parasitism 60\%; Tuero et al. 2007), while the frequency of Screaming Cowbird parasitism in Bay-winged Cowbird nests is 93\% (De Mársico et al. 2010).

\section{Data Collection and Analysis}

We captured 21 Shiny Cowbirds (13 females and 8 males) and 13 Screaming Cowbirds ( 8 females and 5 males) using walk-in funnel traps baited with millet. Each cowbird was banded with a unique color-ring combination and was also given a unique head-mark by decoloring the distal end of head feathers with hair bleach (Gloag et al. 2014) to facilitate individual identification in video recordings made during the low light of pre-sunrise when cowbird egg laying occurs (see below). Cowbirds were fitted with radiotransmitters weighing $1.2 \mathrm{~g}$ (model PicoPip Ag392 from Biotrack, Wareham, UK, or model A2455 from Advanced
Telemetry Systems, Isanti, Minnesota, USA), which corresponded to $<3 \%$ of cowbirds' weights. We glued radio-transmitters to birds' backs using a cyanoacrylate adhesive and an activator (Loctite 401 and Loctite 770, respectively; Henkel, Düsseldorf, Germany). The procedure of marking the cowbird and fitting the radiotransmitter took $<15$ min. Transmitters either fell off the birds after a period of time or were removed if birds were recaptured and had been tracked for at least six days (mean time that birds carried transmitters $=35.8 \pm 3.6$ days, range $=6-68$ days, $n=34$ ). Radio-tagged cowbirds were filmed parasitizing nests (see below) and behaved normally.

We tracked each bird over 3-6 consecutive days. We located radio-tagged individuals on foot using a threeelement Yagi antenna and a hand-held receiver (model Sika from Biotrack, Wareham, UK). The radio-tracking schedule included burst sampling, with sessions lasting from 05:00 hours to 12:00 hours and from 16:00 hours to dusk, with a minimum sampling interval of $15 \mathrm{~min}$ between fixes for each individual. We recorded between 3 and 15 fixes for each bird in each session (Table 1). We tracked the birds until we achieved visual contact and then recorded the location using a GPS device (eTrex Legend HCx, Garmin, Olathe, Kansas, USA). When we could not achieve visual contact, we assumed that the location of the bird was the one recorded when the sensitivity of the receiver was set at the minimum gain (i.e. the bird was within a radius of $\sim 2-3 \mathrm{~m}$ ). We also recorded the bird's behavior, which was classified as feeding, nonfeeding (any of several activities including perching, grooming, and singing), or roosting. To determine locations of roosts, we tracked cowbirds after dark.

We estimated morning daily range for each cowbird as the $100 \%$ minimum convex polygon (MCP) using the adehabitatHR package (Calenge 2006) in $R$ version 3.0.1 ( $R$ Development Core Team 2013). We used 100\% MCP estimates instead of $95 \%$ MCP because our interest was to determine the entire area used by cowbirds. For all range size calculations we excluded the record of the roost where the individual spent the previous night. We obtained data from three or more consecutive days of tracking for 10 female and 6 male Shiny Cowbirds and 8 female and 5 male Screaming Cowbirds (total: 141 cowbird-days). We used the morning ranges of these individuals to calculate the cumulative area used for each individual during the period it was tracked and to determine the percentage of the area used in one day that overlapped the area used in the preceding days.

As part of other studies (Gloag et al. 2013, 2014, Fiorini et al. 2014), we placed microcameras with infrared lights (Color 420 line CCD microcamera, Handykam, Redruth, Cornwall, UK) connected to digital video recorders (PVR1000 or PVR500 ECO, LawMate, Austin, Texas, 
TABLE 1. Estimates of daily morning ranges for female and male Shiny and Screaming cowbirds that were radio-tracked during three or more consecutive days in the breeding seasons (October-February) of 2010-2011 and 2011-2012 at Buenos Aires province, Argentina. To calculate daily morning ranges, we considered the average daily ranges of each individual and then the average of the individuals. We estimated daily morning range overlap as the percentage of the area used one day that overlapped with the area used during the previous days.

\begin{tabular}{lcccc}
\hline & \multicolumn{2}{c}{ Shiny Cowbirds } & & \multicolumn{2}{c}{ Screaming Cowbirds } \\
\cline { 2 - 3 } & Females & Males & & Females \\
\hline Number of individuals & 10 & 6 & 8 & Males \\
Number of morning fixes per individual & $6.5 \pm 1.7$ & $6.6 \pm 1.2$ & $7.0 \pm 1.6$ & $7.3 \pm 1.5$ \\
Daily morning range (ha) & $21.9 \pm 5.0$ & $45.3 \pm 13.7$ & $24.7 \pm 5.1$ & $24.2 \pm 11.1$ \\
Daily morning range overlap (\%) & $59 \pm 6$ & $54 \pm 9$ & $47 \pm 7$ & $77 \pm 11$ \\
\hline
\end{tabular}

USA) at Chalk-browed Mockingbird nests during their laying period. We recorded nest activity from $\sim 04: 30$ hours to at least 08:30 hours to detect parasitism events by Shiny Cowbird females. We filmed 15 parasitism events that involved radio-tagged females, with at least 4 different individuals filmed (in 3 of 15 events we could not identify the female accurately). These videos indicated that several radio-tagged females searched for and parasitized mockingbird nests during the period in which they were radiotracked.

\section{Statistical Analysis}

We used general linear mixed models (GLMM) to evaluate differences between the sexes, for each species, in daily morning ranges. We included sex as a fixed factor, individual ID as a random factor, and the areas of the consecutive daily ranges for each individual as the repeated measure. To test whether there was an effect of time of the breeding season when radio-tracking was carried out, we included time of breeding (beginning, middle, or end of the breeding season) as a covariate in the models. We also used general linear mixed models to evaluate, for each species, differences between the sexes in cumulative ranges, with sex and time as fixed factors and individual ID as a random factor. We checked for normality of the residuals for all models. We conducted these analyses using the nlme package (Pinheiro et al. 2013) in R version 3.0.1. When the interaction term was significant, we calculated the simple effects to evaluate differences between groups.

To study pair association in Screaming Cowbirds, we used data from 3 females and 3 males who were captured in pairs (i.e. the individuals were caught together in the same trap). We tracked these birds throughout the day during 3-6 consecutive days after capture. Every $15 \mathrm{~min}$ we recorded whether the female and the male were within $2 \mathrm{~m}$ of each other (spatially associated) or $>2 \mathrm{~m}$ from each other (not associated). We also carried out random sampling of the locations of these individuals and tracked them and the association with their potential mates during $1 \mathrm{hr}$ in the morning and $1 \mathrm{hr}$ in the afternoon for 5 additional days. The time of sampling varied from day to day and sampling was not necessarily carried out on consecutive days. In this way, we assessed pair association over a 20-day period for the 3 pairs. As a control for random association, we used 2 females and 2 males who were captured separately and monitored during the same period. We compared the frequency of fixes in which individuals of each pair (captured together vs. captured separately) were associated during the morning and afternoon.

All statistical tests were two-tailed, and differences were considered significant at $P<0.05$. Values reported are means $\pm \mathrm{SE}$.

\section{RESULTS}

The majority of fixes in the morning corresponded to nonfeeding activities for both Shiny Cowbirds (females: 81 \pm 3\%; males: $77 \pm 4 \%$ ) and Screaming Cowbirds (females: $60 \pm 6 \%$; males: $61 \pm 6 \%$ ). For most individuals, the mean size of the morning daily range varied between 20 and 45 ha (Table 1). We found a difference between the sexes in morning daily range for Shiny Cowbirds, $\left(\mathrm{F}_{1,14}=4.8, \mathrm{P}=\right.$ $0.04)$, with males' daily morning ranges twice as large as those of females (Table 1). In contrast, we did not find a difference between the sexes for Screaming Cowbirds $\left(F_{1,11}\right.$ $=0.1, \mathrm{P}=0.75$; Table 1). There was no significant effect of time of the breeding season on morning daily range for Shiny Cowbirds $\left(F_{2,58}=1.72, P=0.20\right)$ or Screaming Cowbirds $\left(F_{2,49}=0.05, P=0.95\right)$. For both species, there was extensive (50-60\%) overlap in the morning ranges of individual females on consecutive days (Table 1, Figure 1A). In addition, morning ranges of different cowbird females tracked during the same day overlapped (Figure 1B). We were able to radio-track one female Shiny Cowbird during both breeding seasons, and the overlap of the areas that she used between years was 71\% (Figure 1C).

We also found differences between the sexes in Shiny Cowbirds' morning cumulative ranges, and these differences depended on time as the interaction of sex $\times$ time was significant $\left(F_{4,45}=4.0, P=0.007\right.$; Figure $\left.2 \mathrm{~A}\right)$. Simple effects indicated that the cumulative ranges were greater 


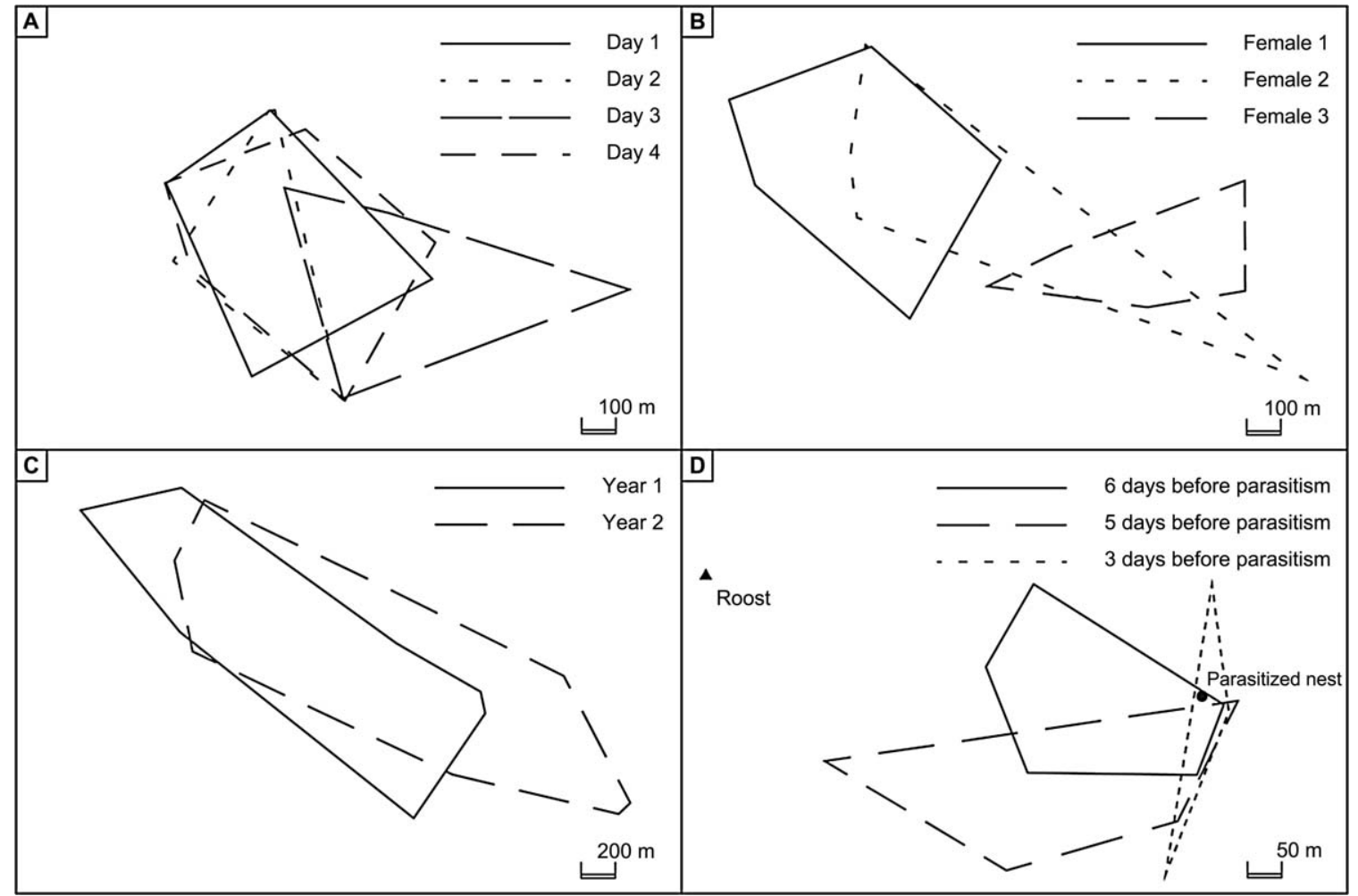

FIGURE 1. Morning ranges of (A) one Shiny Cowbird female radio-tracked during four consecutive days, and (B) three Shiny Cowbird females tracked simultaneously on the same day. (C) Cumulative morning ranges of one Shiny Cowbird female radio-tracked over two consecutive breeding seasons. (D) Morning ranges of one Shiny Cowbird female tracked during the days prior to the event of parasitism. The triangle indicates the location of the roost where the female spent the night before the parasitism event, and the circle shows the location of the nest that was parasitized. Data were collected during the breeding seasons (October-February) of 2010-2011 and 2011-2012 at Buenos Aires province, Argentina.

for males than for females at days $4\left(F_{1,11}=5.8, P=0.03\right)$ and $5\left(F_{1,6}=10.1, P=0.02\right)$. We did not find differences between the sexes in cumulative ranges of Screaming Cowbirds $\left(F_{1,11}=0.1, P=0.71\right.$; Figure $\left.2 \mathrm{~B}\right)$. For Shiny Cowbirds, cumulative ranges were $\sim 70$ ha for females and $\sim 170$ ha for males, while for Screaming Cowbirds they were $\sim 70-80$ ha for both sexes (Figure 2). There was no significant effect of time of the breeding season for either species $(P>0.05$ for both models).

During the afternoon, we found female Shiny Cowbirds within their morning ranges, mostly engaged in feeding activities in flocks of conspecifics, but we did not observe males in their morning ranges. One male was regularly located feeding $\sim 1.5 \mathrm{~km}$ away from his morning range, and a second male was once located feeding in a cattle feedlot $\sim 6 \mathrm{~km}$ from his morning range. We were unable to locate the other males. For Screaming Cowbirds, we located both sexes during the afternoon feeding within their morning ranges. They were often associated with flocks ( 20-30 individuals) of Brown-and-yellow Marshbirds (Pseudoleistes virescens) or with other pairs ( 4-6 individuals) of Screaming Cowbirds.
Most radio-tracked Shiny Cowbirds and Screaming Cowbirds used one roost, which was maintained throughout the breeding season. Cowbirds rarely commuted to other, smaller roosts. They departed from the roost between 04:50 and 06:25 hours and returned to the roost between 19:30 and 20:00 hours. We video-recorded 15 events of parasitism by radio-tagged Shiny Cowbird females (see Supplementary Material). For five of these events we also recorded the location of the female at the roost the previous night. In one case, we recorded the time at which the female departed from the roost and videorecorded the parasitism event at the nest $3 \mathrm{~min}$ later. For the rest of the video-recorded cases, we did not have the exact time of departure from the roost on the morning of the parasitism event, but we recorded departure times on the days preceding the parasitism event. On average, females left the roost $9.7 \pm 4.0 \mathrm{~min}$ before sunrise (range $=$ $21 \mathrm{~min}$ before sunrise to $9 \mathrm{~min}$ after sunrise, $n=7$ ), and were video-recorded parasitizing host nests $9.6 \pm 4.3 \mathrm{~min}$ before sunrise (range $=19 \mathrm{~min}$ before sunrise to $6 \mathrm{~min}$ after sunrise, $n=5$ ). This indicates that females flew directly from the roost to the host nest, which was within 

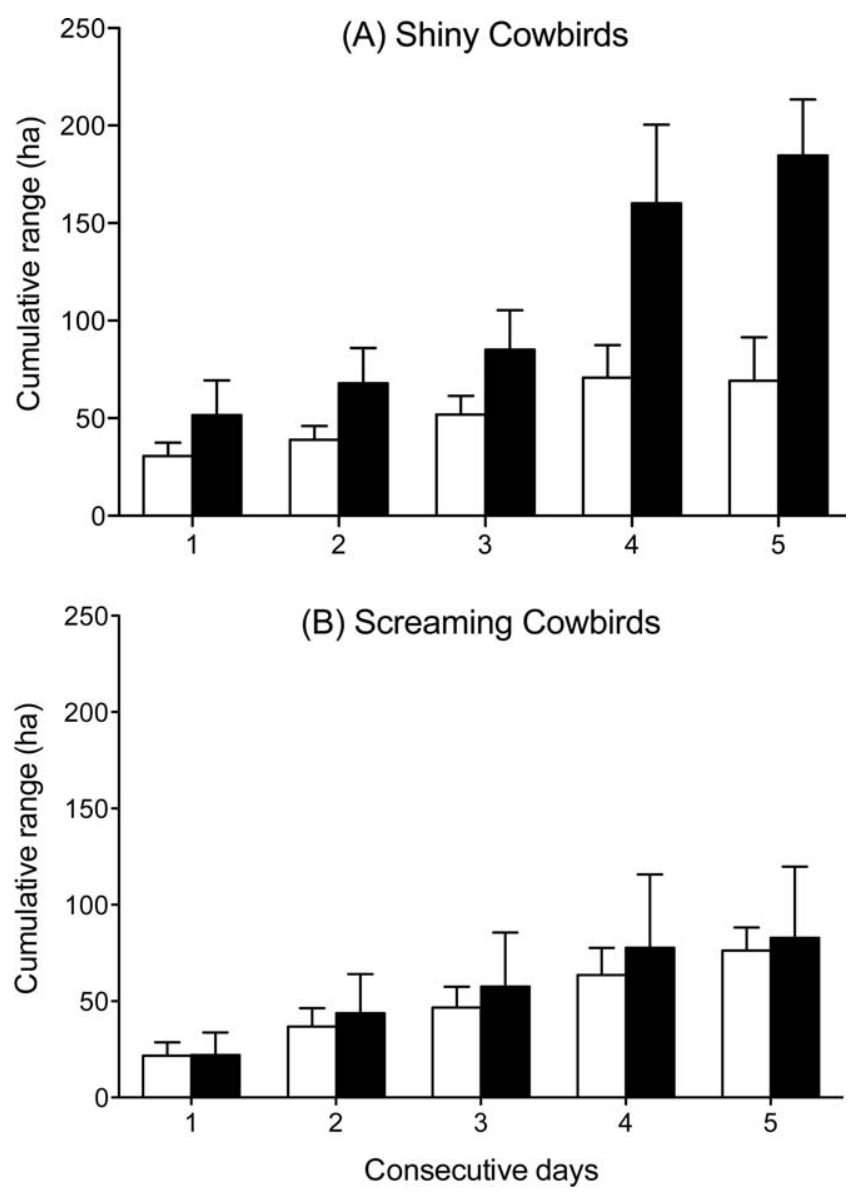

FIGURE 2. Cumulative range areas (in ha) in consecutive days for female (white bars) and male (black bars) Shiny Cowbirds (A) and Screaming Cowbirds (B). Data correspond to 10 female and 6 male Shiny Cowbirds and 8 female and 5 male Screaming Cowbirds that were radio-tracked during three or more consecutive days during the breeding seasons (OctoberFebruary) of 2010-2011 and 2011-2012 at Buenos Aires province, Argentina.

the area monitored by the female during previous days (Figure 1D). On average, the distance between the roost and the nest that was parasitized was $676 \pm 69 \mathrm{~m}(n=5)$.

We found a strong association between male and female Screaming Cowbirds that were caught together (Table 2). The percentage of fixes in which females and males were found within $2 \mathrm{~m}$ of each other varied between $74 \%$ and $100 \%$ during the morning and $42 \%$ and $83 \%$ during the afternoon. In contrast, where females and males had been trapped separately, the percentage of fixes in which they were associated varied between $0 \%$ and $2 \%$.

\section{DISCUSSION}

Our results present evidence for the use of relatively constant areas for nest searching by Shiny Cowbirds and Screaming Cowbirds. Females of both species showed considerable overlap in their morning ranges in consecutive days, and the addition of new area to their ranges decreased over time. In Shiny Cowbirds, morning daily ranges and cumulative morning ranges were greater for males than for females, but there were no differences between the sexes in Screaming Cowbirds. We also showed that female and male Screaming Cowbirds that were caught together were associated in the majority of their fixes, as opposed to those that were caught separately, which indicates social monogamy in this species.

This is the first study to analyze ranging behavior of Shiny Cowbirds and Screaming Cowbirds at the time that they were searching for host nests, and the first in which range was determined daily and recorded over several consecutive days. Most previous studies, conducted on Brown-headed Cowbirds (i.e. Dufty 1982, Rothstein et al. 1984, Teather and Robertson 1985, Thompson 1994, Gates and Evans 1998, Hahn et al. 1999), estimated home range by recording one fix per day on several days, and therefore were unable to evaluate whether females maintained stable daily ranges throughout the breeding season. Our study shows that Shiny and Screaming cowbird females tend to use the same area in the morning on consecutive days and that daily morning ranges are relatively small. Male Screaming Cowbirds have daily and cumulative morning ranges similar to those of females, while daily and cumulative morning ranges in male Shiny Cowbirds are considerably larger than those of females. Some studies have shown that the sex with the larger home range has a larger hippocampus and performs better at a spatial memory task in the laboratory (Gaulin and FitzGerald 1986, Gaulin et al. 1990). In the Shiny Cowbird, females have a larger hippocampus than males (Reboreda et al. 1996), while having a smaller home range. This finding supports the hypothesis that spatial cognition is adaptively specialized in brood-parasitic cowbirds. Remembering the precise location of multiple host nests, and not the mapping of a larger home range, would impose higher spatial cognition demands on females and would explain the observed sexual dimorphism in hippocampus volume.

Because we tracked females for only 5-6 consecutive days, we cannot rule out the possibility that cumulative ranges throughout the breeding season are considerably larger than those observed during the tracking period. However, we consider this possibility unlikely because: (1) the addition of new area to a female's range tended to decrease over the time tracked; and (2) for several Shiny and Screaming cowbird females, we carried out random sampling of the location of the individual after the tracking period and nearly all of the fixes were within the previously estimated cumulative range.

We also observed that in all cases in which we were able to video-record parasitism by radio-tagged Shiny Cowbird females and record their location at the roost the nights 
TABLE 2. Association between pairs of female and male Screaming Cowbirds caught either together or separately, expressed as the percentage of fixes at which females and males were found within $2 \mathrm{~m}$ of each other (associated) or farther away (not associated) during the morning and the afternoon. Total number of fixes recorded for each pair during each radio-tracking period is given in parentheses.

\begin{tabular}{llrr}
\hline & & \multicolumn{2}{c}{ Female-male association (\%) } \\
\cline { 3 - 4 } & Captured & \multicolumn{1}{c}{ Morning } & Afternoon \\
\hline Pair 1 & Together & $100(n=48)$ & $42(n=38)$ \\
Pair 2 & Together & $74(n=27)$ & $83(n=24)$ \\
Pair 3 & Together & $90(n=50)$ & $63(n=40)$ \\
Pair 4 & Separately & $2(n=46)$ & $0(n=24)$ \\
Pair 5 & Separately & $0(n=46)$ & $0(n=22)$ \\
\hline
\end{tabular}

before, the female flew directly from the roost to the host nest, which was within the area monitored by the female over the preceding days. Gloag et al. (2013) found that more than $90 \%$ of parasitism events by Shiny Cowbirds occurred in a short time window before sunrise. Similarly, Screaming Cowbird females parasitized Bay-winged Cowbird nests in a short time window before sunrise (R. C. Scardamaglia personal observation). These findings indicate that at the time a female departs from the roost she knows the location of the nest to parasitize, likely because during previous days she has located that nest within her morning range.

Other studies conducted in Common Cuckoos (Cuculus canorus; Honza et al. 2002, Vogl et al. 2002, 2004) and Brown-headed Cowbirds (Hahn et al. 1999) have analyzed the use of space by these brood parasites at the time they search for host nests. Honza et al. (2002) showed that only half of nest visits resulted in egg laying, which indicates that cuckoo females visit host nests not only to parasitize them, but also to monitor their changes through time. Vogl et al. (2002, 2004) showed that radio-tracked female cuckoos have habitat preferences when searching for suitable host nests, and spend significantly more time in those specific habitats on laying days than on nonlaying days. Lastly, Hahn et al. (1999) showed that female cowbirds were more closely related to young cowbirds in nests inside than outside their home ranges, which indicates that they preferentially lay eggs within their home ranges. These and our results indicate that typical behavior of cuckoos and cowbirds during the breeding season consists of searching for potential hosts' nests within relatively small areas, monitoring these nests through time, and returning for laying when the state of the host's nest is appropriate.

Our study also provides indirect evidence of the social mating systems of Shiny and Screaming cowbirds. Mason (1987) studied pair formation in these species by analyzing data on recaptures and suggested that the pattern of association between sexes was consistent within species, with a promiscuous mating system in Shiny Cowbirds and a monogamous mating system in Screaming Cowbirds. However, the co-occurrence of birds at traps does not provide reliable information on the spatial association of the birds throughout the day nor on the extent of social monogamy. Our results showed that both daily and cumulative morning ranges of male Shiny Cowbirds were 2-3 times larger than those of females, which is consistent with males following different females and a socially polygynous or promiscuous mating system. In contrast, the daily and cumulative morning ranges of Screaming Cowbirds were similar in males and females, and pairs that were caught together remained spatially associated in most morning fixes, which is consistent with social monogamy.

To summarize, our results show that Shiny and Screaming cowbird females have characteristic and relatively small individual home ranges within which they search for host nests during the breeding season. The use of constant areas, together with adaptive specializations such as an enlarged hippocampus and better spatial memory, would facilitate recall of the location of potential host nests through time and thus allow cowbirds to synchronize parasitism with host laying.

\section{ACKNOWLEDGMENTS}

We thank Fundación Elsa Shaw de Pearson for allowing us to conduct this study at the Reserve El Destino. We would also like to thank Ros Gloag and Vanina Fiorini for recording the videos at mockingbird nests, and María Cecilia de Mársico, Ros Gloag, and Vanina Fiorini for useful comments on an earlier version of the manuscript. R. C. Scardamaglia was supported by a fellowship from the Consejo Nacional de Investigaciones Científicas y Técnicas (CONICET). J. C. Reboreda is a Research Fellow of CONICET. This work was supported by grants from Agencia Nacional de Promoción Científica y Tecnológica and University of Buenos Aires. All work complied with Argentinean law, and was undertaken with permission from Organismo Provincial de Desarrollo Sostenible, Province of Buenos Aires, Argentina.

\section{LITERATURE CITED}

Alderson, G. W., H. L. Gibbs, and S. G. Sealy (1999). Determining the reproductive behaviour of individual Brown-headed Cowbirds using microsatellite DNA markers. Animal Behaviour 58:895-905.

Calenge, C. (2006). The package adehabitat for the R software: A tool for the analysis of space and habitat use by animals. Ecological Modelling 197:516-519.

Clayton, N., J. C. Reboreda, and A. Kacelnik (1997). Seasonal changes of hippocampus volume in parasitic cowbirds. Behavioural Processes 41:237-243. 
Cruz, A., T. Manolis, and R. Andrews (1990). Reproductive interactions of the Shiny Cowbird Molothrus bonariensis and the Yellow-hooded Blackbird Agelaius icterocephalus in Trinidad. Ibis 132:436-444.

De Mársico, M. C., and J. C. Reboreda (2008). Egg-laying behavior in Screaming Cowbirds: Why does a specialist brood parasite waste so many eggs? The Condor 110:143-153.

De Mársico, M. C., B. Mahler, and J. C. Reboreda (2010). Reproductive success and nestling growth of the Baywing parasitized by Screaming and Shiny cowbirds. Wilson Journal of Ornithology 122:417-431.

Dufty, A. M. (1982). Movements and activities of radio-tracked Brown-headed Cowbirds. The Auk 99:316-327.

Ellison, K., S. G. Sealy, and H. L. Gibbs (2006). Genetic elucidation of host use by individual sympatric Bronzed Cowbirds (Molothrus aeneus) and Brown-headed Cowbirds (M. ater). Canadian Journal of Zoology 84:1269-1280.

Feare, C., and M. Zaccagnini (1993). Roost departure by Shiny Cowbirds (Molothrus bonariensis). Hornero 13:292-293.

Fiorini, V. D., and J. C. Reboreda (2006). Cues used by Shiny Cowbirds (Molothrus bonariensis) to locate and parasitise Chalk-browed Mockingbird (Mimus saturninus) nests. Behavioral Ecology and Sociobiology 60:379-385.

Fiorini, V. D., R. Gloag, J. C. Reboreda, and A. Kacelnik (2014). Strategic egg destruction by brood parasitic cowbirds? Animal Behaviour. In press.

Fiorini, V. D., D. T. Tuero, and J. C. Reboreda (2009). Shiny Cowbirds synchronize parasitism with host laying and puncture host eggs according to host characteristics. Animal Behaviour 77:561-568.

Fraga, R. M. (1986). The Bay-winged Cowbird (Molothrus badius) and its brood parasites: Interactions, coevolution and comparative efficiency. Ph.D. dissertation, University of California, Santa Barbara, CA, USA.

Fraga, R. M. (1998). Interactions of the parasitic Screaming and Shiny cowbirds (Molothrus rufoaxillaris and M. bonariensis) with a shared host, the Bay-winged Cowbird (M. badius). In Parasitic Birds and Their Hosts: Studies in Coevolution (S. I. Rothstein and S. K. Robinson, Editors), Oxford University Press, New York, pp. 173-193.

Friedmann, H. (1929). The Cowbirds: A Study in the Biology of Social Parasitism. C. C. Thomas, Springfield, IL, USA.

Gates, J. E., and D. R. Evans (1998). Cowbirds breeding in the Central Appalachians: Spatial and temporal patterns and habitat selection. Ecological Applications 8:27-40.

Gaulin, S. J., and R. W. FitzGerald (1986). Sex differences in spatial ability: An evolutionary hypothesis and test. American Naturalist 127:74-88.

Gaulin, S. J., R. W. FitzGerald, and M. S. Wartell (1990). Sex differences in spatial ability and activity in two vole species (Microtus ochrogaster and M. pennsylvanicus). Journal of Comparative Psychology 104:88-93.

Gloag, R., V. D. Fiorini, J. C. Reboreda, and A. Kacelnik (2012). Brood parasite eggs enhance egg survivorship in a multiply parasitized host. Proceedings of the Royal Society B 279: 1831-1839.

Gloag, R., V. D. Fiorini, J. C. Reboreda, and A. Kacelnik (2013). The wages of violence: Mobbing by mockingbirds as a frontline defence against brood-parasitic cowbirds. Animal Behaviour 86:1023-1029.
Gloag, R., V. D. Fiorini, J. C. Reboreda, and A. Kacelnik (2014). Shiny Cowbirds share foster mothers but not true mothers in multiply parasitized mockingbird nests. Behavioral Ecology and Sociobiology 68:681-689.

Goguen, C. B., D. R. Curson, and N. E. Mathews (2011). Costs of multiple parasitism for an avian brood parasite, the Brownheaded Cowbird (Molothrus ater). Canadian Journal of Zoology 89:1237-1248.

Guigueno, M. F., D. A. Snow, S. A. MacDougall-Shackleton, and D. F. Sherry (2014). Female cowbirds have more accurate spatial memory than males. Biology Letters. doi:10.1098/rsbl.2014. 0026

Hahn, D., J. Sedgwick, I. Painter, and N. Casna (1999). A spatial and genetic analysis of cowbird host selection. Studies in Avian Biology 18:204-217.

Honza, M., B. Taborsky, M. Taborsky, Y. Teuschl, W. Vogl, A. Moksnes, and E. Roskaft (2002). Behaviour of female Common Cuckoos, Cuculus canorus, in the vicinity of host nests before and during egg laying: A radiotelemetry study. Animal Behaviour 64:861-868.

Hoover, J. P. (2003). Multiple effects of brood parasitism reduce the reproductive success of Prothonotary Warblers, Protonotaria citrea. Animal Behaviour 65:923-934.

Kattan, G. (1997). Shiny Cowbirds follow the "shotgun" strategy of brood parasitism. Animal Behaviour 53:647-654.

Langmore, N. E., and R. M. Kilner (2007). Breeding site and host selection by Horsfield's Bronze-Cuckoos, Chalcites basalis. Animal Behaviour 74:995-1004.

Lowther, P. E. (2013). Lists of Victims and Hosts of the Parasitic Cowbirds, version 04 Jul 2013. The Field Museum, Chicago, IL, USA. http://fm1.fieldmuseum.org/aa/Files/lowther/CBList.pdf

Mason, P. (1987). Pair formation in cowbirds: Evidence found for Screaming but not Shiny cowbirds. The Condor 89:349-356.

McLaren, C., B. E. Woolfenden, H. Gibbs, and S. G. Sealy (2003). Genetic and temporal patterns of multiple parasitism by Brown-headed Cowbirds (Molothrus ater) on Song Sparrows (Melospiza melodia). Canadian Journal of Zoology 81:281286.

Moskát, C., Z. Barta, M. E. Hauber, and M. Honza (2006). High synchrony of egg laying in Common Cuckoos (Cuculus canorus) and their Great Reed Warbler (Acrocephalus arundinaceus) hosts. Ethology Ecology \& Evolution 18:159167.

Norman, R., and R. J. Robertson (1975). Nest-searching behavior in the Brown-headed Cowbird. The Auk 92:610-611.

O'Keefe, J., and L. Nadel (1978). The Hippocampus as a Cognitive Map. Oxford University Press, Oxford, UK.

Payne, R., L. Payne, J. Woods, and M. Sorenson (2000). Imprinting and the origin of parasite-host species associations in broodparasitic Indigobirds, Vidua chalybeata. Animal Behaviour 59: 69-81.

Peer, B., and S. G. Sealy (1999). Laying time of the Bronzed Cowbird. Wilson Bulletin 111:137-139.

Pinheiro, J., D. Bates, S. DebRoy, and D. Sarkar (2013). nlme: Linear and Nonlinear Mixed Effects Models. R package version 3.1-113. http://www.inside-r.org/r-doc/nlme/

R Development Core Team (2013). R: A language and environment for statistical computing. R Foundation for Statistical Computing, Vienna, Austria. 
Reboreda, J. C., N. Clayton, and A. Kacelnik (1996). Species and sex differences in hippocampus size in parasitic and nonparasitic cowbirds. Neuroreport 7:505-508.

Rivers, J. W., S. Young, E. G. Gonzalez, B. Horton, J. Lock, and R. C. Fleischer (2012). High levels of relatedness between Brownheaded Cowbird (Molothrus ater) nestmates in a heavily parasitized host community. The Auk 129:623-631.

Rothstein, S. I., and S. K. Robinson (1998). The evolution and ecology of avian brood parasitism. In Parasitic Birds and their Hosts: Studies in Coevolution (S. I. Rothstein and S. K. Robinson, Editors), Oxford University Press, New York, pp. 356.

Rothstein, S. I., J. Verner, and E. Stevens (1984). Radio-tracking confirms a unique diurnal pattern of spatial occurrence in the parasitic Brown-headed Cowbird. Ecology 65:77-88.

Scott, D. M. (1991). The time of day of egg laying by the Brownheaded Cowbird and other icterines. Canadian Journal of Zoology 69:2093-2099.

Sherry, D., M. Forbes, M. Khurgel, and G. Ivy (1993). Females have a larger hippocampus than males in the brood-parasitic Brown-headed Cowbird. Proceedings of the National Academy of Sciences USA 90:7839-7843.

Soler, M., and T. Pérez-Contreras (2012). Location of suitable nests by Great Spotted Cuckoos: An empirical and experimental study. Behavioral Ecology and Sociobiology 66:13051310.

Spottiswoode, C. N., R. M. Kilner, and N. B. Davies (2012). Brood parasitism. In The Evolution of Parental Care (N. J. Royle, P. T. Smiseth, and M. Kölliker, Editors), Oxford University Press, Oxford, UK, pp. 226-243.

Teather, K. L., and R. J. Robertson (1985). Female spacing patterns in Brown-headed Cowbirds. Canadian Journal of Zoology 63:218-222.
Teather, K. L., and R. J. Robertson (1986). Pair bonds and factors influencing the diversity of mating systems in Brown-headed Cowbirds. The Condor 88:63-69.

Teuschl, Y., B. Taborsky, and M. Taborsky (1998). How do cuckoos find their hosts? The role of habitat imprinting. Animal Behaviour 56:1425-1433.

Thompson, F. R., III (1994). Temporal and spatial patterns of breeding Brown-headed Cowbirds in the midwestern United States. The Auk 111:979-990.

Trine, C. L. (2000). Effects of multiple parasitism on cowbird and Wood Thrush nesting success. In Ecology and Management of Cowbirds and Their Hosts (J. N. M. Smith, T. L. Cook, S. I. Rothstein, S. K. Robinson, and S. G. Sealy, Editors), University of Texas Press, Austin, TX, USA, pp. 135-144.

Tuero, D. T., V. D. Fiorini, and J. C. Reboreda (2007). Effects of Shiny Cowbird Molothrus bonariensis parasitism on different components of House Wren Troglodytes aedon reproductive success. Ibis 149:521-527.

Vogl, W., B. Taborsky, M. Taborsky, Y. Teuschl, and M. Honza (2004). Habitat and space use of European Cuckoo females during the egg laying period. Behaviour 141:881-898.

Vogl, W., M. Taborsky, B. Taborsky, Y. Teuschl, and M. Honza (2002). Cuckoo females preferentially use specific habitats when searching for host nests. Animal Behaviour 64:843-850.

Wiley, J. (1988). Host selection by the Shiny Cowbird. The Condor 90:289-303.

Supplementary Material. A radio-tagged female Shiny Cowbird makes a pre-sunrise visit to a Chalk-browed Mockingbird nest, where she attempts to puncture the existing eggs before laying her own. The radio-tag and its antenna can be easily identified on the back of the female cowbird. 